\title{
Preparing, Facilitating, Assessing: A Reflection on Digital Humanities
}

\section{Consultations}

\author{
E. LEIGH BONDS
}

Digital Humanities Librarian, The Ohio State University, Columbus, OH USA

\begin{abstract}
A key component of the Digital Humanities Librarian's work, the consultation, involves the skills of listening, questioning, parsing, and planning aided by an understanding of the broader digital humanities landscape, project requirements, and the campus environment. Productive consultations provide researchers the direction they need to get their projects started or advanced to the next stage, often resulting in sustained, collaborative engagement that makes assessing the impact of this work challenging.
\end{abstract}

\section{Keywords:}

Digital humanities; digital scholarship; consultations; assessment.

\section{Introduction}

Recent discussions with my colleagues have prompted me to reflect on an integral part of my work as a Digital Humanities Librarian (DHL) — the consultation. Specifically, I've been contemplating what makes a consultation productive, how I developed my consultation skills, and how best to assess and report those interactions to show impact. Central to this form of interaction are the abilities "to listen to someone give their idea for a project [and] mentally parse it and match it up with an accomplishable plan," Miriam Posner (2018) recently tweeted. As such, the digital humanities (DH) consultation is akin to the reference interview and the writing conference in that it involves asking a series of 
open-ended questions to clarify the project's aims and scope.1 Likewise, it's related to the research consultation as defined by Devin Savage (2015), and Lorie A. Kloda and Alison J. Moore (2016) in that it occasionally involves preparation beforehand-although in my experience, it more often involves research and/or experimenting afterward. While each of these forms of consultation require specific expertise and skills in listening, questioning, parsing, and planning, the DH consultation additionally hinges on a foundational knowledge of the broader DH landscape, project requirements, and the campus environment.

For new DHLs and others working with researchers on DH projects like subject librarians or members of digital scholarship teams, determining what to learn before, what to ascertain during, and what to assess after consultations can seem daunting. Even DHLs who've been in these roles for some time find it challenging to determine ways to further hone their craft. In this piece, I delve into the foundational knowledge I find instrumental in facilitating productive DH consultations, consider the key components of the DH consultation, and discuss new ways to assess the impact of consultations with faculty and student researchers. Throughout, I share the resources that have informed my thinking about these matters, and in the end, I call for DHLs to reflect on their own practice and share what's proven essential to its development.

\section{Preparing for Consultations: Mapping the DH Landscape}

Alan Liu (2015) opens his "Map of the Digital Humanities" with an explanation of how "map" is apropos for an ontology of DH: "A map is not a definition. It is a way of moving around and showing others how to get from somewhere they know to somewhere unknown within a reasonable compass." Having a general understanding of the map of $\mathrm{DH}$ - of the relationships between the different features of the terrain, the specific methods employed by the different fields involved in DH study-enables the DHL to determine where a project lies on the map (field of study), what features it likely has based on that location (methods), and how it generally relates to other areas. The qualifiers "likely" and "generally" reflect the ever-changing nature of the map: the terrain changes as methods and tools are developed, adapted, and applied in new ways, making it necessary to refresh the map from time to time, to stay abreast of new developments in the landscape. 
This general understanding of fields and methods edifies the more granular knowledge of the DH landscape-tools and projects. Being familiar with the tools used for specific methods and having a few examples of projects using specific methods and specific tools prove invaluable during consultations. In "How Did They Make That?" (2013), Miriam Posner models the kind of reverse engineering DHLs do in order to explain to researchers what tools and technical skills were involved in developing a particular project and what resources are available to teach them that tool or skill. Among the many resources for information on DH methods and tools, the DH Toychest (Liu, 2017) organizes its lists of tutorials and tools by method, and The Programming Historian (2018) organizes its tool lessons by phases of the research process and general topics. Focusing on text analysis, TAPoR 3 (2018) curates a list of tools by application and Methodica (2018) provides "recipes" with lists of ingredients, process steps, and links to resources. LibGuides Community (2018) provides a wealth of additional resources by searching the name of a method or a tool in its database of over 593,000 published LibGuides. As for collecting exemplary projects, DH centers' websites often have pages featuring affiliated projects, Digital Humanities Awards (2017) maintains lists of nominated and winning projects, and DH Commons (2018) includes lists of projects in various stages of development. Annual DH conferences (and conference abstracts) and the National Endowment for the Humanities (NEH) Office of Digital Humanities (ODH) award winners (and sample application narratives) are other sources of information about projects and work underway.2 Regular browsing, reviewing, and bookmarking sources like these has helped me build an extensive list of "go to" resources that I rely on during consultations.

Because faculty often seek DHLs' advice and support with the curricular integration of DH, having a familiarity with DH pedagogy practices and resources proves useful. In "How Not to Teach Digital Humanities," Ryan Cordell (2016) offers sound advice for "curricular incursion" (But Don't Panic section, para. 3) drawing from his own experience designing graduate and undergraduate courses with DH components. Providing a complete curriculum, Intro to Digital Humanities (Drucker, Kim, Salehian, \& Bushong, 2013) presents DH topics ranging of from visualization to text encoding to GIS mapping as lesson plans that include readings, resources, and exercises, and includes tutorials on specific tools like Omeka, Gephi, Voyant, and GeoCommons. Even those lessons that refer to outdated 
versions of certain tools maintain value in demonstrating how to structure lessons on these topics and scaffold the learning. A recent issue of Digital Humanities Quarterly (2017) edited by Emily Christina Murphy and Shannon R. Smith focuses on undergraduate education in DH with articles addressing program models, disciplinarity and DH pedagogy, tool development, and professional concerns. Resources like these not only expand the DHL's knowledge of the DH landscape, but also expand their "go to" lists of references for consultations.

\section{Preparing for Consultations: Identifying Project Requirements}

The ability to parse project requirements during a consultation depends on a DHL's understanding of project design and development. Everything I learned about these DH basics when preparing for a DH position-that I didn't gain from actually working on collaborative projects-I learned from Jennifer Guiliano's and Simon Appleford's (2013) DevDH lecture series. Still very relevant today as evidenced by its inclusion on Natalia Ermolaev's (2017) “Pitching a DH Project Workshop Resources" (a list of "go to" resources I recently discovered), the series guides researchers through the design and development process, covering topics like how to formulate humanities digital research questions, build collaborative teams, manage projects, maintain project documentation, manage data, and end a project. Everything I learned about data curation during that preparation, I learned at a Digital Humanities Data Curation (DHDC) Institute workshop at the Maryland Institute for Technology in the Humanities. Julia Flanders's and Trevor Muñoz’s (2012) “An Introduction to Humanities Data Curation" (a reading for that workshop) includes a discussion of the unique features of humanities data that I've found helpful for thinking about and explaining curation to researchers. All of these matters-from formulating research questions to curating data-inevitably arise during consultations.

Accompanying those matters, of course, are the more specific concerns of project requirements. Thinking of projects in terms of stages has given me a clear set of requirements to discuss with researchers regardless of which stage their project may be in when they initially consult with me. Grounded in my understanding of project design and development, my conception of the "project lifecycle" has four stages (the terms of which I adopted from the NEH ODH digital humanities advancement grants): idea, startup, 
implementation, sustainability. At the idea stage, the researcher develops and refines the research question, reviews existing work in the area, and defines the project's scope. The start-up stage involves generating or gathering digital content/data, developing management plans for the project and the data, consulting with other experts (e.g. application development, copyright, statistics), selecting platforms and/or tools, finding collaborators, acquiring hosting, and experimenting (e.g. testing tools or building a site mock-up to develop a proof of concept). The implementation stage extends the proof of concept to a fully realized project (e.g. fully functional database, dynamic website, or complete analysis results) that is then promoted to the research community. This stage may also involve updating, revising, recovering, and expanding existing projects. If funded, collaborators secure resources and services for project management, further development, and sustained hosting in this stage. The final stage of the lifecycle concerns the project's sustainability. In addition to determining long-term goals and assessment measures for an established project, sustainability involves maintaining the project's site with regular updates or migrating it a new platform to ensure compatibility and access. Furthermore, this stage involves curating the project's data, code, and/or screen captures/web scrapes in a repository for long-term access. Thinking about projects in terms of stages with specific requirements generates a framework to guide questions and discussion about these concerns during consultations.

\section{Preparing for Consultations: Scanning the Campus Environment}

Understanding the broad DH landscape and specific project requirements is prerequisite to investigating the campus environment for $\mathrm{DH}$ interests and efforts, and for resources and services to support that work. "Needs assessments benefit from a person or team familiar with the national and international DH ecosystem," the Educause Center for Analysis and Research (ECAR) working group explains (Anne et al., 2017). "This broader perspective can be helpful in alerting local stakeholders to opportunities, challenges, and controversies in the field" (Anne et al., 2017). Additionally, that "broader perspective" enables the person or team conducting the scan to recognize DH in researchers' interests, skills, and work (i.e. research, teaching, and directing student research) and to narrow their 
focus on campus units most liable to offer the specific resources and services researchers need.3 It's important, therefore, to determine what options are available and where to direct researchers for resources and services like digitization (full- and self-service for print, audio, video, and 3D), development (both customizing open-source platforms and building custom applications), hosting, software, training, repository depositing, and additional consulting (e.g. funding, copyright, statistics, IRB) — if, of course, those resources and services exist on campus. Knowing who's doing what and who's offering what ultimately gives the DHL a bird's-eye view of DH on campus that very few others have, making them an invaluable asset to researchers and a key advocate for developing or expanding resources and services to meet researchers' needs.

\section{Facilitating Productive Consultations}

The reply to "Tell me about your project" that begins each initial consultation typically includes the essential bits of information: the topic, the research question, the data, and what they want to accomplish. Usually, they also share what they've already completed, what they've tried, what technical skills they have, who else they've spoken with about their project, who their collaborators are, and whether they have-or plan to apply for-funding. Follow-up questions fill in the gaps in the information provided, clarify terms, or seek to better understand the research question, the data, and the project's aims.

As the researcher's vision of the project comes into focus, the foundational knowledge of the broader DH landscape, project requirements, and the campus environment proves indispensable for interpreting and translating it. From the topic, the research question, the data, and the aims, the DHL can discern the appropriate method(s) and the applicable tool(s). From the additional information shared, they can discern the project's current stage, the requirements for that particular stage, and the training the researcher needs to learn the technical skill(s) required by the method(s) and tool(s). While discussing these determinations, the available options, and the feasibility of the project's scope, the DHL can show the researcher projects that apply a particular method to a research question that may or may not be in their own discipline, and projects that utilize a specific tool to achieve similar aims. Seeing others' projects often clarifies for the researcher how the method(s) and tool(s) can be used in their own project and prompts 
them to consider possibilities they hadn't before. The DHL can then explain what additional resources and services are available on campus to further support their project and begin sketching a plan for getting the work underway.

The primary objective of the initial consultation is to provide the researcher with the direction they need to get their project started or advance it to the next stage. Typically, the researcher leaves our initial consultation with a list of action items and either an idea of when we should touch base or a scheduled appointment for a follow-up consultation. I'll admit, however, that some researchers leave with clearer direction than others: having all the answers on the spot is not always possible-and, quite honestly, I haven't consulted with a researcher yet who has that expectation. As mentioned earlier, it's sometimes necessary to do research following a consultation to find resources or to experiment with a tool to make certain that it will meet the project's needs. Other times, it's necessary to refer the researcher to another expert or unit on campus, to contact a colleague to discuss the project, or to schedule a joint appointment with a colleague and the researcher. Regardless of which the case may be, I always follow-up the initial consultation with an email containing links to any resources, tools, or projects mentioned during the consultation; the contact information for others I recommended the researcher meet with; and information about the campus DH Slack and working groups, workshops, or events that may be of interest and relevant to their work.

Subsequent consultations maintain the goal of advancing the researcher's work further, but they tend to be working sessions focused on specific steps in the project's development like creating controlled vocabularies for metadata, structuring data, sketching page designs, or writing a data management plan for a grant proposal. Instead of the listening, questioning, parsing, and planning that characterizes the initial consultation, these consultations involve brainstorming (whiteboarding), teaching, demonstrating, or guiding decision making. On occasion, I've accompanied researchers to meetings with application developers to serve as a translator of sorts, explaining the research aims of the project to the developers and the user interface, design, and data modeling options to the researcher. For a few, I've become even more engaged as a collaborator on the project, contributing my own technical skills and content knowledge to move the project forward.

Similarly, I have consulted and collaborated on the integration of DH into courses, 
advising on syllabus and course development, and teaching methods or tools during class sessions. The initial consultations with faculty and graduate students about curricular integration relate closely to those focused on projects: from the reply to "Tell me what you have in mind," the DHL learns the course topic, the kind of project(s) they want their students to build, what data their students will be using, and ultimately what they want their students to learn. Because the design, development, and requirements for DH projects in courses and DH research projects are ostensibly the same, the approach to the consultations for each is very similar. The DHL gathers the necessary information and makes recommendations about methods, tools, training, and resources based on the learning objectives.

\section{Assessing Impact}

Productive DH consultations result in sustained, collaborative engagement with researchers, guiding and supporting them through the project lifecycle, continually parsing and planning for the project's next stage. As other DHLs and digital scholarship librarians have confirmed, the nature of our work makes assessing impact a challenge.5 Quantitative data like the number of consultations a DHL conducts in a given period of time or numerical post-consultation satisfaction ratings fail to convey what was actually accomplished by those interactions. It's important, therefore, to capture qualitative data to relate the nature of this engagement and the resulting impact. If, for example, a consultation leads a researcher to a tool, online tutorials, and a hosting service that results in a proof of concept, chronicling that progress in a narrative provides a clearer account of impact. Statements from the researchers about the role the consultation(s) played in their works' progress-gathered formally through post-consultation surveys, in presentations, or in letters of support for annual reviews and/or informally in emails or conversationsfurther enhance those narratives and substantiate impact.

When a collaboration develops, the consultation's impact can be further gauged by the DHL's specific contributions to the collaboration and/or the achievement of the project's desired outcomes. Both the level of contribution(s) and the desired outcome(s) are often set in the early stages of the collaboration, as Alex Gil (2018) explains:

For [projects] I'm directly involved in, we measure "success" against definitions of 
success at the beginning of the project. Those usually are often very concrete and not hard to measure: paper published? conference papers delivered? were teaching goals met (if the thing is built and it works, then yes)? how many articles on the press? research question answered? tests passing on the code? data entered by $\mathrm{x}$ date? deal made with $\mathrm{X}$ institution? etc. In other words, those are narrative driven. Of course, the contribution(s) and outcome(s) occasionally shift during a project's development as opportunities and challenges emerge-additional factors to account for in the narrative.

Moreover, assessing the impact of consultations and collaborations in this way contributes directly to assessing the broader impact of programs. Micah Vandegrift (2018) focuses assessment on "program building," viewing consultations as a factor in broader programmatic impact: "We do tasks (ex. consultations), that lead to projects (ex. a digital cultural heritage exhibit), that lead to initiatives (exploring humanities data curation), that lead to a program (humanities data project infrastructure and workflows)." Assessing consultations and ensuing collaborations, therefore, must not only relate the impact on the individual researcher and project, but also on the program of which they're a fundamental part.

\section{Conclusion}

Consultations provide DHLs opportunities for meaningful engagement with researchers. From guiding a researcher through refining a research question and defining scope to determining long-term goals and making curation decisions, the DHL's expertise, knowledge, and insight prove invaluable not only to building projects, but also to cultivating relationships. The work DHLs do-listening, questioning, parsing, and planning-to help researchers find ways to transform their ideas into realities builds ethos that's validated every time they schedule follow-ups, refer other researchers for consultations, or invite us to teach class sessions or to collaborate on projects. For me, striving for real impact is reward unto itself.

If this reflection initiates conversations about the essential skills for conducting DH consultations, the DH knowledge requisite for productive consultations, and the means for assessing and reporting impact, then it's served its purpose. The more DHLs share about 
their work-and DH consultations in particular-at conferences and in professional organizations' working groups, the closer we get to determining the characteristics that makes our work productive and impactful, and to developing best practices for the different aspects of it. Furthermore, the more we share our assessment frameworks and the annual reports generated using them, the stronger the case for qualitative forms of assessment for DH and digital scholarship work becomes. 


\section{Notes}

1 For information about reference interview questions, see "3.0 Listening/Inquiring" in the Reference and User Services Association's (2013) Guidelines for Behavioral Performance of Reference and Information Service Providers. For information about writing conference questions, see the "Student Conferences" section (p. 75-78) in Cheryl Glenn's and Melissa A. Goldthwaite's (2008) The St. Martin's Guide to Teaching Writing.

2 For a calendar of digital humanities conferences, see the Digital Library Federation's DLF Community Calendar (2018).

3 For a detailed discussion of an approach and framework for an environmental scan, see my recent "First Things First: Conducting an Environmental Scan" (Bonds, 2018).

4 For the DHDC workshop's introductory readings, workshop wiki and slide decks, and useful links, see "Learning Materials" (Digital Humanities Data Curation Institute, 2013).

5 For the discussion on this topic I posed to the Digital Library Federation Digital Scholarship Working Group (2018), see "DS/DH Assessment." 


\section{References}

Anne, K. M., et al. (2017, May 31). Building Capacity for Digital Humanities: A Framework for Institutional Planning. Retrieved from

https://er.educause.edu/ /media/files/library/2017/5/ewg1702.pdf?la=en

Appleford, S., \& Guiliano, J. DevDH: Development for the Digital Humanities (2013). Retrieved from http://devdh.org/lectures/whatnext

Bonds, E. L. (2018, January 31). "First things first: conducting an environmental scan." $d h+l i b$. Retrieved from https://acrl.ala.org/dh/2018/01/31/first-things-first-conducting-an-environmental$\underline{\text { scan }}$

Cordell, R. (2016). "How not to teach digital humanities." Debates in the Digital Humanities. Retrieved from $\underline{\text { http://dhdebates.gc.cuny.edu/debates/text/87 }}$

DH Commons: A Collaboration Hub. (2018). Retrieved from https://dhcommons.org

Digital Humanities Awards: Highlighting Resources in Digital Humanities. (2017). Retrieved from http://dhawards.org

Digital Humanities Data Curation Institute. (2013). "Learning materials." DHDC: Digital Humanities Data Curation. Retrieved from http://www.dhcuration.org/institute/materials

Digital Library Federation. (2018). DLF Community Calendar. Retrieved from https://www.diglib.org/opportunities/calendar

Digital Library Federation Digital Scholarship Working Group. (2018). DS/DH assessment. Discussion posted to https://groups.google.com/forum/?hl=en\#!topic/dlf-dswg/ElEaICrxQo4

Drucker, J., Kim, D., Salehian, I., \& Bushong, A. (2013). Intro to Digital Humanities: Concepts, Methods, and Tutorials for Students and Instructors. Retrieved from 
$\underline{\text { http://dh101.humanities.ucla.edu }}$

Methodica: Digital Text Methods Commons. (2018). Retrieved from http://methodi.ca/

Ermolaev, N. "Pitching a DH project workshop resources." Retrieved from

https://cdh.princeton.edu/media/uploads/documents/2016-

2017 pitching a dh_project resources.pdf

Flanders, J., \& Muñoz, T. (2012). “An introduction to humanities data curation.” DHDC: Digital

Humanities Data Curation. Retrieved from http://www.dhcuration.org/institute/materials

Gil, A. (2018, March 7). DH/DS assessment [Msg 3]. Message posted to

https://groups.google.com/forum/?hl=en\#!topic/dlf-dswg/ElEaICrxQo4

Glenn, C., \& Goldthwaite, M. A. (2008). The St. Martin's Guide to Teaching Writing (6th ed.). Boston, MA: Bedford St. Martin's.

Kloda, L. A., \& Moore, A. J. (2016). "Evaluating reference consultations in the academic library.” Paper presented at the 2016 Library Assessment Conference, Arlington, Virginia. Retrieved from http://old.libraryassessment.org/bm doc/102-moore-2016.pdf

LibGuides Community. (2018). Retrieved from https://community.libguides.com

Liu, Alan. (2015, September 8). "Map of the digital humanities." Retrieved from http://oldsite.english.ucsb.edu/faculty/ayliu/unlocked/dh/map of dh.pptx

Liu, A. (2017, November 4). DH Toychest: Digital Humanities Resources for Project Building. Retrieved from http://dhresourcesforprojectbuilding.pbworks.com/w/page/69244243/FrontPage

miriamkp. (2018, April 25). One of these days I'd like to teach a Digital Scholarship for Librarians class that teaches you how to listen to someone give their idea for a project \& 
mentally parse it and match it up with an accomplishable plan. [Twitter Post]. Retrieved from https://twitter.com/miriamkp/status/989266237300469760

Murphy, E. C., \& Smith, S. R. (Eds.) (2017). Imaging the DH undergraduate: Special issue in undergraduate education in DH. Digital Humanities Quarterly, 11.3. Retrieved from http://www.digitalhumanities.org/dhq/vol/11/3/index.html

Posner, M. (2013, August 29). "How did they make that?" Miriam Posner's Blog. Retrieved from http://miriamposner.com/blog/how-did-they-make-that

The programming historian. (2018). Retrieved from https://programminghistorian.org Reference and User Services Association. (2013). Guidelines for behavioral performance of reference and information service providers. Retrieved from http://www.ala.org/rusa/resources/guidelines/guidelinesbehavioral

Savage, D. (2015). "Not counting what counts: The perplexing inattention to research consultations in library assessment activities." Paper presented at the 2015 Association of College and Research Libraries Conference, Portland, Oregon. Retrieved from http://www.ala.org/acrl/sites/ala.org.acrl/files/content/conferences/confsandpreconfs/2015/Savag e.pdf

Tapor 3. (2018). Retrieved from http://tapor.ca/home

Vandegrift, M. (2018, March 27). Assessment of digital scholarship services. Message posted to http://lists.ala.org/sympa/arc/dss-1/2018-03/msg00031.html 
This is an Accepted Manuscript of an article published by Taylor \& Francis in International Information \& Library Review on 7 February 2019, available online:

http://www.tandfonline.com/10.1080/10572317.2018.1506873. 